\title{
Load Rating versus Reliability Analysis
}

\author{
Allen C. Estes, M.ASCE, ${ }^{1}$ and Dan M. Frangopol, F.ASCE ${ }^{2}$
}

\begin{abstract}
The most common approach to assess the safety of a bridge is load rating. However, this approach cannot quantify the bridge safety in probabilistic terms or fully quantify the structural risk to the bridge. Reliability methods have become an increasingly popular and gradually accepted approach to assess the safety of structures. These methods account for the randomness and correlation of all relevant variables and failure modes in the analysis. This study performs both a load rating analysis and a reliability analysis on the same highway bridge, compares the results, and discusses the strengths and limitations of each approach.
\end{abstract}

CE Database subject headings: Load criteria; Limit states; Bridges, highway; Structural reliability; System reliability; Live loads.

\section{Introduction}

Agencies charged with operating and maintaining highway bridges are responsible to the public for the safety of those structures. Bridge managers must understand how much load a bridge can safely carry and communicate that information to the public. The most common approach is to assign a load rating to a bridge that specifies its load carrying capacity. The efforts of the American Association of State Highway and Transportation Officials (AASHTO) and the National Cooperative Highway Research Program have helped to provide an accepted standard (White et al. 1992). AASHTO (2000) provides widely used rating methods.

Reliability methods have become an increasingly popular and gradually accepted approach to assess the safety of structures. There is some risk associated with every structure. A reliability approach quantifies that risk in probabilistic terms by accounting for the randomness and correlation of all relevant variables in the analysis. This study performs a load rating analysis and a reliability analysis on the same highway bridge, compares the results, and discusses the strengths and limitations of each approach.

\section{Load Rating}

A load rating analysis was conducted on Bridge E-17-AH, a Colorado highway bridge located in the Denver metro area, using the Bridge Analysis and Rating System (BARS) program (BARS 1988). The bridge shown in Fig. 1, described in detail in Estes

\footnotetext{
${ }^{1}$ Associate Professor, Dept. of Civil and Mechanical Engineering, United States Military Academy, West Point, NY 10996.

${ }^{2}$ Professor, Dept. of Civil, Environmental, and Architectural Engineering, Univ. of Colorado, Boulder, CO 80309-0428.
}

and Frangopol (1999), is a simply supported, three-span bridge which carries four lanes of traffic. The superstructure consists of a reinforced concrete slab supported by nine standard shape steel girders. The rating system uses a load factor approach which includes inventory and operating ratings. The inventory rating is the lower of the two ratings and represents the load level at which a structure is safe for an infinite period of time (White et al. 1992) (assuming no deterioration of the structure). The operating rating is the absolute maximum load that should be allowed on the bridge under any circumstances. The live load associated with the load rating is the AASHTO design truck (AASHTO 1998).

For Bridge E-17-AH, the load rating is based on the moment capacity of the concrete slab and the shear, moment, and serviceability capacities of the most critical girder. The load rating for the overall bridge is the lowest rating of any single failure mode and is a single deterministic value that represents the strength of the bridge. The AASHTO design truck is located in the middle of the slab and girder for the moment analysis and at the end of the girder for the shear computation. The serviceability analysis is the same as the moment analysis, except the elastic section modulus rather than the plastic section modulus is used in the calculations. The inventory and operating load ratings for Bridge E-17-AH are shown in Table 1 . The analysis produces a rating factor (RF). The inventory $\left(\mathrm{RF}_{\mathrm{inv}}\right)$ and operating $\left(\mathrm{RF}_{\mathrm{opr}}\right)$ rating factors for the moment failure modes, for example, are

$$
\begin{gathered}
\mathrm{RF}_{\mathrm{inv}}=\frac{M_{u}-\delta M_{d \ell}}{\delta \varepsilon M_{\ell \ell}} \\
\mathrm{RF}_{\mathrm{opr}}=\frac{M_{u}-\delta M_{d \ell}}{\delta M_{\ell \ell}}
\end{gathered}
$$

where $M_{u}=$ ultimate moment capacity; $M_{d \ell}$ and $M_{\ell \ell}=$ moment effects from the dead load and live loads, respectively; $\delta=1.3$; and $\varepsilon=1.67$. The HS rating and the U.S. ton capacity are obtained by multiplying the rating factor by 20 and 36 , respectively. The bridge is given an inventory rating of HS 17.8 and an operating rating of HS 29.7, based on the serviceability score on each. 


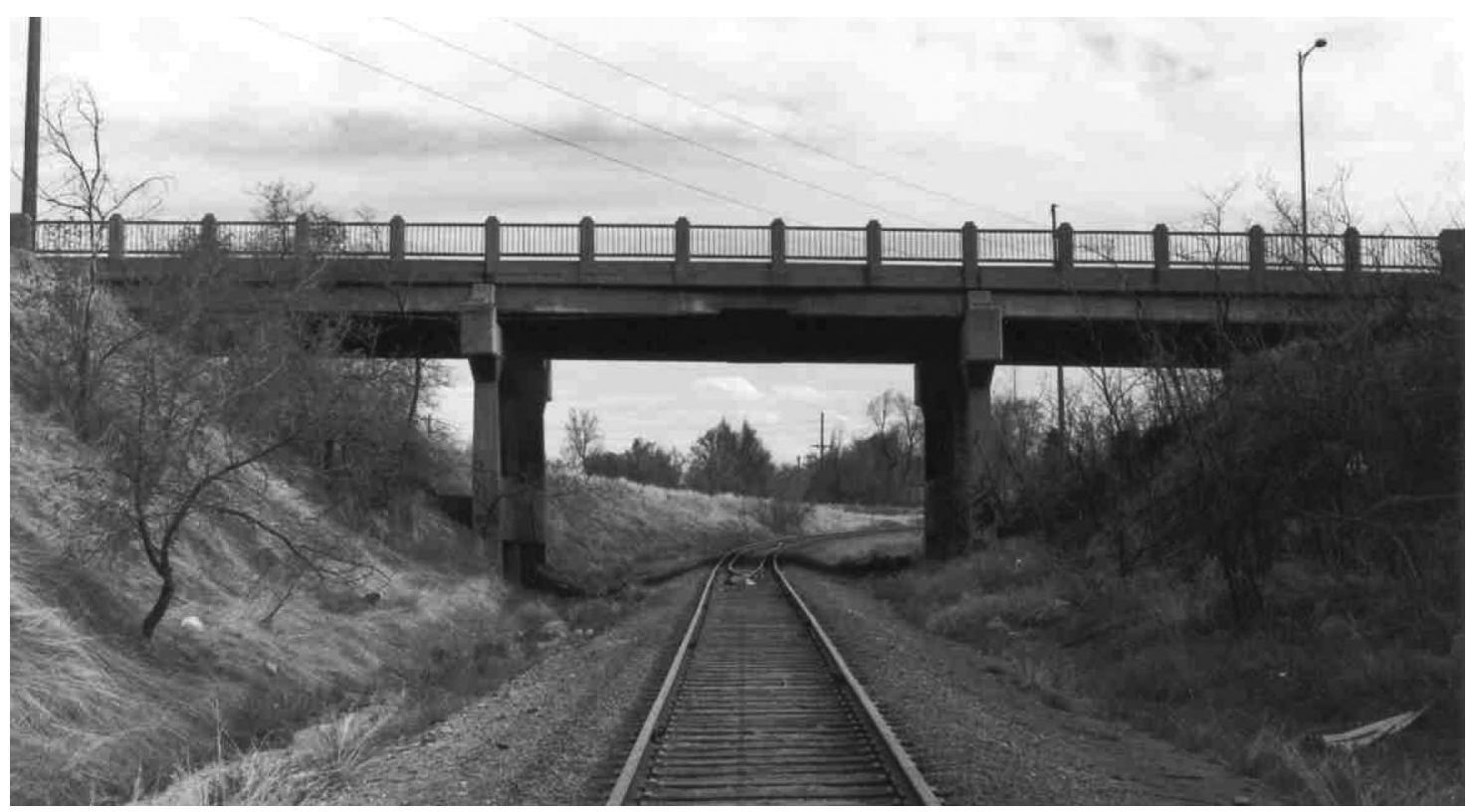

Fig. 1. Colorado State highway bridge E-17-AH

\section{Reliability Analysis}

The same equations that were used for the load rating were used to compute the reliability of the bridge with respect to the same failure modes of slab moment, girder moment, and girder shear. In a reliability analysis, the uncertainty and correlation associated with the variables in the limit state equations are quantified and the result is a probability of failure of the structure rather than a load rating. The random variables included uncertainties associated with material strength, dimensions that could not easily be measured, live loads, unit weight of materials, and modeling uncertainty. A listing of the random variables, their source, and their associated parameters are provided in Table 2 (Estes and Frangopol 1999). The three limit state equations $g(1)=0, g(2)=0$, and $g(3)=0$ associated with the failure of the slab due to moment, the girder due to shear, and the girder due to moment, respectively, are (Estes and Frangopol 1999):

$$
\begin{aligned}
g(1)= & \gamma_{\mathrm{mfc}}\left[0.349 \lambda_{\text {rebar }} f_{y} \lambda_{D_{\text {eff }}}-\frac{0.3844 \lambda_{\text {rebar }}^{2} f_{y}^{2}}{244.8 f_{c}^{\prime}}\right]-0.137 \lambda_{\text {asph }} \\
& -0.471 \lambda_{\text {conc }}-4.26 \lambda_{\text {trk }}=0
\end{aligned}
$$

Table 1. Summary of Load Ratings for Colorado Highway Bridge E-17-AH

\begin{tabular}{lcccc}
\hline \multicolumn{5}{c}{ Inventory and operating ratings } \\
\hline Failure mode & Rating factor & HS rating & $\begin{array}{c}\text { U.S. ton } \\
\text { capacity }\end{array}$ & $\begin{array}{c}\text { Metric ton } \\
\text { capacity }\end{array}$ \\
\hline Slab & 1.487 & 29.8 & 53.56 & 48.59 \\
& $(2.479)$ & $(49.6)$ & $(82.96)$ & $(80.98)$ \\
Girder: Flexure & 1.035 & 20.7 & 37.26 & 33.80 \\
& $(1.725)$ & $(34.5)$ & $(62.1)$ & $(56.34)$ \\
Girder: Shear & 3.230 & 64.6 & 116.3 & 105.5 \\
& $(5.40)$ & $(108.0)$ & $(194.4)$ & $(176.4)$ \\
Serviceability & 0.829 & 17.8 & 32.12 & 29.14 \\
& $(1.487)$ & $(29.7)$ & $(53.53)$ & $(48.56)$ \\
\hline
\end{tabular}

Note: Operating ratings are indicated in parentheses.

$$
\begin{aligned}
g(2)= & 10.55 F_{y} \gamma_{\mathrm{msg}}-18.04 \lambda_{\text {conc }}-5.26 \lambda_{\text {asph }}-2.89 \lambda_{\text {steel }} \\
& -28.33 V_{\text {trk }-i} D F_{i} i_{\text {beam }}=0 \\
g(3)= & 39.8 F_{y} \gamma_{\mathrm{mfg}}-197.65 \lambda_{\text {conc }}-57.64 \lambda_{\text {asph }}-31.7 \lambda_{\text {steel }} \\
& -M_{\text {trk }-i} D F_{i} i_{\text {beam }}=0
\end{aligned}
$$

To obtain a comparison with the load rating, the reliability analysis was initially completed using a deterministic live load equal to the HS-20 truck. Table 3 shows the results obtained from the Reliability of Systems (RELSYS) program (Estes and Frangopol 1998). The probability of failure $\left(P_{f}\right)$ is expressed through the reliability index $(\beta)$, where $P_{f}=\Phi(-\beta)$ and $\Phi$ is the distribution function of the standard normal variate.

The major difference between the reliability and the load rating results is the relative disparity in importance of the slab and girder-shear failure modes. The load rating indicates that the slab (HS 29.8) can safely carry less than one-half of the load that the girder (HS 64.6) can sustain with respect to shear failure, yet the two failure modes have almost equal reliabilities. The difference is caused by the relative uncertainty of those variables not common to both equations (such as the respective model uncertainty factors, the strength of the concrete and steel, and the effective depth of the reinforcing steel) and the sensitivity of the variables to the overall result.

A load rating analysis informs the bridge manager as to which trucks can safely cross a particular bridge. For Bridge E-17-AH, for example, the maximum load allowed on the slab is an HS 49.6 equivalent truck, while the girder with respect to shear could handle an HS 108.0 equivalent truck. One would expect that a reliability analysis on the slab and girder using these two trucks, respectively, would produce a similar level of safety. Table 4 indicates otherwise. The reliabilities are quite different as the operating and inventory loads are applied with respect to the three failure modes. The level of disparity is not the same comparing the inventory and operating load results. For example, when the girder is subjected to its inventory load with respect to shear and moment, the girder is safer with respect to shear $\left(\beta_{\text {shear }}\right.$ $=4.21, \beta_{\text {moment }}=3.89$ ). When subjected to their operating loads, 
Table 2. Random Variables in Reliability Analysis of Bridge E-17-AH

\begin{tabular}{|c|c|c|c|}
\hline Definition and units of random variables & Notation & $\begin{array}{l}\text { Mean value and } \\
\text { standard deviation }\end{array}$ & Reference \\
\hline Uncertainty factor: Live load shear on interior girders ${ }^{\mathrm{a}}$ & $\mathrm{V}_{\mathrm{trk}-i}$ & $(1.38 ; 0.1656)^{\mathrm{b}}$ & Nowak (1993) \\
\hline Yield strength of steel reinforcing in concrete deck (MPa) & $f_{y}$ & $(386.1 ; 42.5)$ & Nowak (1993) \\
\hline Yield strength of steel in girders (MPa) & $F_{y}$ & $(252.5 ; 29.0)$ & Nowak (1993) \\
\hline Uncertainty in live load girder distribution: Interior girders & $\mathrm{DF}_{i}$ & $(1.309 ; 0.163)$ & Zokaie et al. (1991) \\
\hline Compressive strength of concrete ( 28 day) $(\mathrm{MPa})$ & $f_{\mathrm{c}}^{\prime}$ & $(19.0 ; 3.42)$ & Nowak et al. (1994) \\
\hline Uncertainty factor: Impact on girders & $i_{\text {beam }}$ & $(1.14 ; 0.114)$ & Nowak et al. (1994) \\
\hline Live load moment on interior girders $(\mathrm{kN} \mathrm{m})$ & $M_{\text {trk- } i}$ & $(579.4 ; 69.6)$ & Nowak (1993) \\
\hline Live load moment on exterior girders $(\mathrm{kN} \mathrm{m})$ & $M_{\text {trk-e }}$ & $(474.1 ; 56.9)$ & Nowak (1993) \\
\hline Uncertainty factor: Weight of truck on bridge & $\gamma_{\text {trk }}$ & $(1.38 ; 0.1656)$ & Nowak (1993) \\
\hline Model uncertainty: Shear in steel & $\gamma_{\mathrm{msg}}$ & $(1.14 ; 0.137)$ & Nowak (1993) \\
\hline Model uncertainty: Flexure in steel & $\gamma_{\mathrm{mfg}}$ & $(1.11 ; 0.128)$ & Nowak (1993) \\
\hline Model uncertainty: Concrete flexure deck & $\gamma_{\mathrm{mfc}}$ & $(1.02 ; 0.061)$ & Nowak and Yamani (1995) \\
\hline Uncertainty factor: Weight of asphalt & $\lambda_{\text {asph }}$ & $(1.0 ; 0.25)$ & Nowak (1993) \\
\hline Uncertainty factor: Weight of concrete & $\lambda_{\text {conc }}$ & $(1.05 ; 0.105)$ & Nowak (1993) \\
\hline Uncertainty factor: Reinforcing steel area in concrete & $\lambda_{\text {rebar }}$ & $(1.0 ; 0.015)$ & Nowak et al. (1994) \\
\hline Uncertainty factor: Effective depth of reinforcing steel & $\lambda_{\text {Deff }}$ & $(1.0 ; 0.02)$ & Lu et al. (1994) \\
\hline Uncertainty factor: Weight of steel & $\lambda_{\text {steel }}$ & $(1.03 ; 0.082)$ & Nowak (1993) \\
\hline
\end{tabular}

${ }^{\mathrm{a}}$ Random variables without units are dimensionless.

${ }^{\mathrm{b}}$ Mean values $\mu$ and standard deviation $\sigma$ are indicated in parentheses $(\mu ; \sigma)$

the girder is safer with respect to moment $\left(\beta_{\text {shear }}=2.40, \beta_{\text {moment }}\right.$ $=2.46$ ).

The system reliability was obtained by modeling the bridge as a series (weakest-link) system of the three failure modes. The RELSYS program accounts for correlation between variables and failure modes in its system reliability calculations. Typically, the reliability of a series system is less than the reliability of any individual component unless the failure modes are perfectly correlated. In this example, the reliability of the interior girder due to flexure $(\beta=4.0)$ is so much lower than the reliabilities of the other two modes that it dominates the system. If the reliabilities with respect to the three failure modes were closer together, and the failure mode correlation was weak, the system reliability would have been significantly lower than the reliability of any individual component. In fact, the highest the series system reliability can possibly be is the reliability of the weakest component. The overall load rating on the bridge is the deterministic equivalent of the system reliability index. Taking the overall load rating of the bridge as the value of the lowest rated failure mode is unconservative because the exact correlation between failure modes is not considered.

Table 3. Comparison of Load Ratings to Reliability Indices for Colorado Bridge E-17-AH Using a Deterministic HS-20 Truck

\begin{tabular}{lccc}
\hline Failure mode & $\begin{array}{c}\text { Inventory rating } \\
(\mathrm{HS})\end{array}$ & $\begin{array}{c}\text { Operating rating } \\
(\mathrm{HS})\end{array}$ & $\begin{array}{c}\text { Reliability index } \\
(\beta)\end{array}$ \\
\hline Slab & 29.8 & 49.6 & 6.72 \\
Girder: Shear & 64.6 & 108.0 & 6.81 \\
Girder: Flexure & 20.7 & 34.5 & 4.00 \\
Serviceability & 17.8 & 29.7 & - \\
System & 17.8 & 29.7 & 4.00 \\
\hline
\end{tabular}

\section{Live Load Models}

Using a deterministic HS-20 truck for the bridge load was valuable for a direct comparison to a load rating, but in reality, the live load on the bridge is one of the most uncertain variables in the analysis. A large number of bridge live load models have been proposed, usually as a result of field observations or weigh-inmotion studies. Quantifying the live load is difficult because the live load effect is a combination of individual truck weights, the spacing of axles, and the relative position of trucks on the bridge. This paper considers two models: Ghosn and Moses (1986) and Nowak (1993).

Based on the results from a large number of sites, Ghosn and Moses (1984) developed a numerical integration approach to calibrate a load prediction equation applied to a range of span lengths. The equation which computes the mean value of the maximum bending moment $M$ over 50 years is: $M$ $=a m W^{*} H_{g i G}$ where the listed variables account for truck configuration $\left(W^{*}\right)$, girder distribution $(g)$, span length $(a$ and $m)$, traffic volume $(H)$, impact $(i)$, and growth $\left(G_{r}\right)$. The coefficient of variation of the maximum moment $\left(V_{M}\right)$ is a function of the coefficients of variation of the variables in the moment equation:

$$
V_{M}=\sqrt{V_{a}^{2}+V_{m}^{2}+V_{W^{*}}^{2}+V_{H}^{2}+V_{g}^{2}+V_{i}^{2}+V_{G_{r}}^{2}}
$$

As expected, the reliability of the girder with respect to moment decreased using the Ghosn live load model. While the reli-

Table 4. Reliability Indices Associated with the HS-20 Truck, Inventory Rated Truck, and the Operating Rated Truck

\begin{tabular}{lccc}
\hline Failure mode & HS-20 load & Inventory load & Operating load \\
\hline Slab & 6.72 & 5.64 & 3.41 \\
Girder: Shear & 6.81 & 4.21 & 2.40 \\
Girder: Moment & 4.00 & 3.89 & 2.46 \\
\hline
\end{tabular}




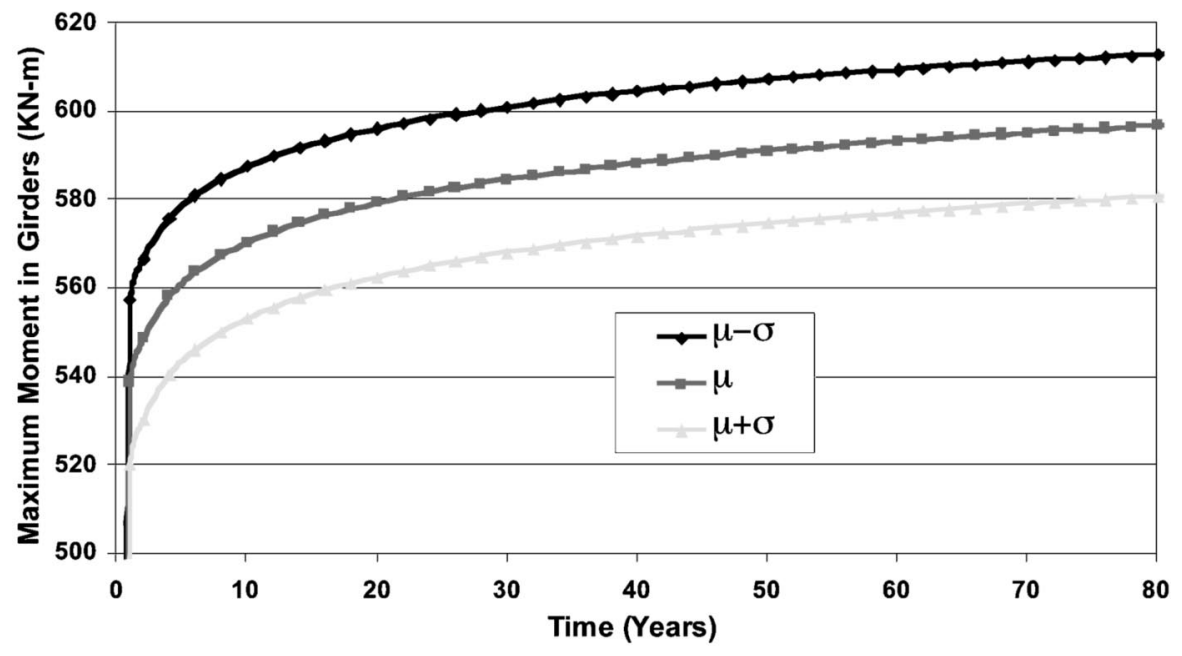

Fig. 2. Maximum moment over time for E-17-AH bridge girder

ability index was $\beta=4.0$ for the girder using an HS-20 truck, the value dropped to $\beta=3.86$ for low volume traffic and $\beta=3.56$ for the average traffic volume. The model forced the traffic to be classified as low (200 trucks per day), average (2,000 trucks per day), or high volume and the average daily truck traffic for Bridge E-17-EH is 850 trucks/day.

A second live load model (Nowak 1993) predicts maximum moments and shears for bridge spans of different lengths. The study assembled data from 9,250 trucks from the Ontario Ministry of Transportation database and included the number of axles, axle spacing, axle loads, and gross weight of vehicles. As the number of occurrences of a truck passing over the bridge becomes larger, the maximum moment approaches a Type I extreme distribution. As a result, it is possible to predict the mean value, $\mu_{M n}$, and the standard deviation, $\sigma_{M n}$, of maximum moment at any time $t$. A similar approach was taken for the shear effects. This model is effective if the average daily truck traffic is known and if it is believed that the trucks in the database are representative of the trucks going over the bridge. Fig. 2 shows the maximum moment on the critical girder of Bridge E-17-AH for various periods of time using this load model.

The reliability analysis of this bridge using the 50 year Nowak live load model produced a reliability index of $\beta=3.21$ with respect to the slab and $\beta=6.22$ and $\beta=2.44$ with respect to the shear and moment of the girder, respectively. The system reliability was dominated by the girder moment where $\beta_{\mathrm{sys}}=2.43$. This live load model produced results similar to those from the operating load rating (Table 4). Table 5 compares the reliability results between the deterministic HS-20 truck, the Ghosn and Moses'

Table 5. Reliability Indices Associated with Load Ratings and Different Live Load Models

\begin{tabular}{lcccc}
\hline & \multicolumn{5}{c}{$\begin{array}{c}\text { Ghosn and } \\
\text { Ghosn and } \\
\text { Moses (1986) } \\
\text { Failure mode }\end{array}$} & $\begin{array}{c}\text { 50 year } \\
\text { (average } \\
\text { load }\end{array}$ & $\begin{array}{c}\text { 50 year (low } \\
\text { traffic) }\end{array}$ & $\begin{array}{c}\text { Nowak } \\
\text { (1993) }\end{array}$ \\
\hline Slab & 6.72 & - & - & 50 year load \\
Girder: Shear & 6.81 & - & - & 3.21 \\
Girder: Flexure & 4.00 & 3.86 & 3.56 & 6.22 \\
System & 4.00 & - & - & 2.44 \\
\hline
\end{tabular}

50 year live load, and the Nowak's 50 year live load. The increased live load has a much larger effect on some failure modes than others, primarily because the live load comprises a different percentage of the total load effect reflected in limit state Eqs. (3)-(5). The reliability of the slab decreased greatly using the Nowak live load model, while the girder shear mode decreased much less. While the HS-20 truck is conservative with regard to the single truck in the live load models, the HS-20 truck is not conservative when the large number of truck occurrences increases the likelihood of encountering an overweight truck at the tail of the distribution. The results from the two live load models did not produce similar results, which emphasizes that reliability analyses are highly dependent on the models that are used for input values. The difference in results is not surprising considering that the models were developed independently and rely on different variables. Live load effect is highly dependent on both structural configuration and location. The live load models might well have produced more similar results on a bridge of a different span length, in a different location, with a different level of traffic volume. A reliability index by itself is meaningless unless the engineer knows what input produced it and, when making a comparison, that the same input was used for both studies.

\section{Conclusions}

Load ratings are a reasonable deterministic approach to determining the strength and allowable load on a bridge. The methodology examines the appropriate failure modes, is consistent among different bridges, and is logical. The load ratings have some limitations that can be overcome using a reliability analysis. The standard AASHTO HS-20 truck is a good conservative and deterministic representation of the typical truck on the highway. However, it does not account for the cumulative effect of a large number of trucks passing over the bridge over a period of time. Using the HS-20 truck, equivalent load ratings for different failure modes do not achieve equivalent levels of safety. Load ratings do not consider redundancy in a structure or correlation between failure modes. A system reliability analysis will consider both.

There are some very good probabilistic live load models available. A reliability analysis overcomes all the listed limitations of the load rating approach and produces a consistent level of safety 
for various failure modes. The disadvantages of the reliability analysis are the increased complexity of calculations, the large amount of input data needed (which may or may not be available), and the ability to influence the results by manipulating the input data. Any reliability approach to evaluating various highway bridges will need to be highly standardized to ensure that the input data used are consistent and provide a valid basis for comparison.

\section{References}

American Association of State Highway and Transportation Officials (AASHTO). (1998). LRFD bridge design specifications, 2nd ed., Washington, D.C.

American Association of State Highway and Transportation Officials (AASHTO). (2000). The manual for maintenance inspection of bridges, Washington, D.C.

BARS. (1988). Bridge analysis and rating system manual, BARS Release 5.0 documentation, C.W. Beilfuss and Associates Inc., Lombard, Ill.

Estes, A. C., and Frangopol, D. M. (1998). "RELSYS: A computer program for structural system reliability analysis." Struct. Eng. Mech., 6(8), 901-919.
Estes, A. C., and Frangopol, D. M. (1999). "Repair optimization of highway bridges using system reliability approach." J. Struct. Eng., 125(7), 766-775.

Ghosn, M., and Moses, F. (1984). Bridge load modeling and reliability analysis, Dept. of Civil Engineering, Case Western Reserve Univ., Cleveland, Ohio.

Ghosn, M., and Moses, F. (1986). "Reliability calibration of a bridge design code." J. Struct. Eng., 112(4), 745-763.

Lu, R., Luo, Y., and Conte, J. (1994). "Reliability evaluation of reinforced concrete beams." Struct. Safety, 14(4), 277-298.

Nowak, A. S. (1993). "Live load model for highway bridges." Struct. Safety, 13(1-2), 53-66.

Nowak, A. S., and Yamani, A. S. (1995). "A reliability analysis for girder bridges." Struct. Eng. Rev., 7(13), 251-256.

Nowak, A. S., Yamani, A. S., and Tabsh, S. W. (1994). "Probabilistic models for resistance of concrete bridge girders." ACI Struct. J., 91(3), 269-276.

White, K. R., Minor, J., and Derucher, K. N. (1992). Bridge maintenance inspection and evaluation, 2nd Ed. Marcel Dekker, New York.

Zokaie, T., Imbsen, R., and Osterkamp, T. (1991). "Distribution of wheel loads on highway bridges." Transportation Research Record. 1290 (Proc. 3rd Bridge Engineering Conf., Vol. 1), Transportation Research Board, Washington, D.C. 